
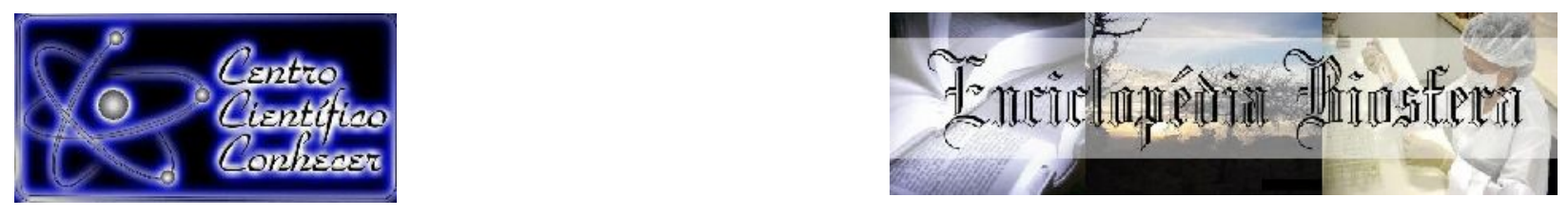

\title{
LEVANTAMENTO FLORISTICO DAS ESPÉCIES UTILIZADAS NO PAISAGISMO DO MUNICÍPIO DE SÃO JOÃO DO SÓTER, MARANHÃO, BRASIL
}

Miguel Sena de Oliveira ${ }^{1}$; Hermeson Cassiano de Oliveira ${ }^{2}$; Alessandro Wagner Coelho Ferreira ${ }^{3}$; Wagner Ribeiro da Silva Junior ${ }^{4}$, Maycon Jordan Costa da Silva ${ }^{5}$

1. Mestrando do Programa de Pós-Graduação em Biodiversidade, Ambiente e Saúde/PPGBAS, CESC/UEMA (E-mail:miguelsena2010@hotmail.com) ,Maranhão,Brasil

2. Professor Adjunto da Universidade Estadual do Piauí (UESPI), Piaui, Brasil

3. Professor Adjunto do Curso de Ciências Biológicas da Universidade Federal do Maranhão (UFMA), Maranhão, Brasil

4, 5. Graduando em Ciências Biológicas-Bacharelado, Universidade Federal do Maranhão (UFMA), Maranhão, Brasil

\section{Recebido em: 06/04/2019 - Aprovado em: 10/06/2019 - Publicado em: 30/06/2019} DOI: 10.18677/EnciBio_2019A80

\begin{abstract}
RESUMO
A vegetação urbana desempenha funções muito importantes nas cidades, proporcionando diversas vantagens as pessoas que vivem nas mesmas, e por isso, devem seguir critérios para escolha e introdução no meio urbano, a fim de que sejam garantidos todos os benefícios sociais e ecológico que as mesmas oferecem. O objetivo desse estudo foi apresentar um inventário das espécies vegetais utilizadas no paisagismo das praças e avenida do município de São João do SóterMA. Os dados foram obtidos através de visitas mensais de maio a outubro de 2018. Foram listados 311 indivíduos, correspondentes a 31 espécies vegetais, 29 gêneros, distribuídos em 20 famílias botânicas, sendo Apocynaceae (Catharanthus roseus (L.), Plumeria rubra L., Allamanda angustifolia Pohl G.Don), Asparagaceae (Agave americana L., Sansevieria trifasciata Prain, Furcraea foetida (L.) Haw.) e Bignoniaceae (Handroanthus heptaphyllus (Vell.) Mattos, Handroanthus serratifolius (Vahl) S.Grose, Tecoma stans (L.) Juss. ex Kunth, com três espécies cada, as famílias mais representativas em número de espécies. Verificou-se que $71 \%$ das espécies da flora utilizada no paisagismo são exóticas e que apenas $29 \%$ são espécies nativas. Copernicia prunifera (Mill.) H.E.Moore (Carnaúba) com 66 indivíduos, foi a espécie mais representativa em número de indivíduos. Diante da elevada utilização das espécies exóticas, sugere-se a criação de um plano diretor municipal, para que esses locais se tornem-se cada vez mais agradáveis para a população e ecologicamente contextualizados.
\end{abstract}

PALAVRAS-CHAVE: Vegetação urbana, Espaços públicos, Espécies exóticas 


\title{
FLORISTIC SURVEY OF VEGETABLE SPECIES USED IN THE LANDSCAPING OF THE MUNICIPALITY OF SÃO JOÃO DO SÓTER, MARANHÃO, BRAZIL
}

\begin{abstract}
Urban vegetation plays a very important role in cities, with people living in urban areas offering a number of advantages and, therefore, must follow criteria for choice and introduction in urban areas, so that all the social and ecological benefits are guaranteed offer. The objective of this study was to present an inventory of the plant species used in the landscaping of the squares and avenue of the municipality of São João do Sóter-MA. The data were obtained through monthly visits from May to October 2018. Have been listed 311 individuals, corresponding to 31 plant species, 29 genera, were distributed in 20 botanical families, being Apocynaceae (Catharanthus roseus (L.), Plumeria rubra L., Allamanda angustifolia Pohl G.Don), Asparagaceae (Agave americana L., Sansevieria trifasciata Prain, Furcraea foetida (L.) Haw.) And Bignoniaceae (Handroanthus heptaphyllus (Vell.) Mattos, Handroanthus serratifolius (Vahl) S.Grose, Tecoma stans (L.) Juss. Ex Kunth, with three species each, the most representative families in number of species. It was verified that $71 \%$ of the species of the flora used in the landscaping are exotic and only $29 \%$ are native species. Copernicia prunifera (Mill.) H.E.Moore (Carnaúba) with 66 individuals was the most representative species in number of individuals. Given the high utilization of exotic species, it is suggested to create a municipal become more and more enjoyable for the population and ecologically contextualized.
\end{abstract}

KEYWORDS: Urban vegetation, Public spaces, Exotic species

\section{INTRODUÇÃO}

A vegetação urbana desempenha funções muito importantes nas cidades, proporcionando diversas vantagens a população urbana, entre as quais: bem estar psicológico; melhor efeito estético; sombra para os pedestres e veículos; protege e direciona o vento; amortece o som, amenizando a poluição sonora; reduz o impacto da água de chuva e o escorrimento superficial, auxilia na diminuição da temperatura, pois, absorve os raios solares e refresca o ambiente pela grande quantidade de água transpirada pelas folhas; melhora a qualidade do ar e preservam a fauna silvestre (PIVETTA; SILVA FILHO, 2002).

Outros benefícios da vegetação urbana é a estabilização das superfícies por meio da fixação do solo pelas raízes das plantas, proteção da qualidade da água, pois dificultam o escorrimento de poluentes para os rios, o equilíbrio do índice de umidade no ar, a proteção das nascentes e dos mananciais, a organização e composição de espaços no desenvolvimento de atividades humanas, a segurança das calçadas como acompanhamento viário, consumo de vegetais e frutas frescas (CARVALHO et al., 2010).

Conhecer a flora urbana faz parte de um programa de estudos que toda cidade deveria se preocupar em desenvolver, visando um plano de arborização que valorize os aspectos paisagísticos e ecológicos com a utilização, principalmente, de espécies nativas. Além dos benefícios que influenciam diretamente a vida do ser humano, do ponto de vista ecológico a arborização urbana é fundamental. Através desta, pode-se salvaguardar a identidade biológica da região, preservando ou cultivando as espécies vegetais que ocorrem em cada região específica (KRAMER; KRUPEK, 2012). 
Para Melo e Romanini (2008) praça é um espaço público de importância para comunidade, convívio social, prática de esportes e atividades de lazer ao ar livre, servindo de palco para manifestações coletivas e que muitas vezes abriga atividades provisórias (feiras, espetáculos musicais, festas folclóricas, dentre outras), propiciando um ambiente agradável de contemplação, leitura, conversa e descanso.

É nítida a empatia das pessoas para com esse tipo de ambiente, e por isso essa relação deve ser mantida e fortalecida pelos setores responsáveis. Para tal, é necessário que profissionais habilitados componham o planejamento e a gestão desses espaços, haja vista que a manutenção da integridade desses espaços e equilíbrio dessa flora urbana é indispensável (SILVA et al., 2017).

As áreas verdes como praças e avenidas, são espaços projetados e inseridos na matriz urbana das cidades com o intuito de melhorar a qualidade de vida da população urbana. E sua ausência, causam sérias consequências e prejuízos para população e meio ambiente, relacionados a diminuição da biodiversidade, alterações das condições climáticas, desconforto térmico, vários tipos de poluição, congestionamentos e risco de acidentes naturais ou humanos (NEVES, 2016; BONFANTI et al., 2017).

Portanto, estudar as espécies vegetais utilizadas no paisagismo urbano, em locais como praças e avenidas, contribui com informações que auxiliam a administração pública municipal, principalmente, a planejar, gerir e a preservar esses espaços, fazendo com que atendam aos aspectos ecológicos, paisagísticos e estéticos na escolha e introdução das espécies nas cidades. Assim, o objetivo deste trabalho foi identificar, por meio de um inventário florístico, as espécies vegetais utilizadas no paisagismo das praças e avenidas do município de São João do SóterMA, com o intuito de fornecer subsídio para órgãos governamentais e a população residente, acerca do planejamento, cuidados e importância da arborização urbana.

\section{Área de estudo}

\section{MATERIAL E METÓDOS}

Localizado na mesorregião Leste maranhense, na Microrregião Caxias, o Município de São João do Sóter (Figura 1), situa-se entre as coordenadas

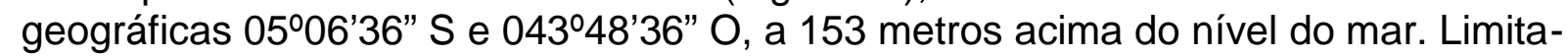
se do Norte ao Leste com o município de Caxias; ao Sul com Senador Alexandre Costa e Parnarama; e a Oeste com Codó e Gonçalves Dias. Seu território compreende uma área de $1.438 \mathrm{~km}^{2}$, população estimada em 18.345 habitantes e uma densidade demográfica de 11,99 habitantes por $\mathrm{km}^{2}$. Apresenta características de Cerrado como vegetação dominante, e uma variação térmica durante 0 ano oscilando entre $21,7^{\circ} \mathrm{C}$ a $32,4^{\circ} \mathrm{C}$. O clima do município, segundo classificação de Köppen é do tipo Aw (tropical, com inverno seco) com estação chuvosa no verão, de dezembro a maio, com médias mensais superiores a $194 \mathrm{~mm}$, e outra nítida estação seca no inverno, de junho a novembro (SÃO JOÃO DO SÓTER, 2011; ALVAREZ et al., 2014; IBGE, 2019).

Em São João do Sóter (Figura 1), foram amostradas todas as praças (três no total) e a única avenida presente no município, são elas: Praça da Cruz (ca. 131 metros), São João Batista (ca. 145 metros), Sóter Mendes (ca. 115 metros) e a Avenida da Esperança (ca. 2.600 metros de extensão) ambas localizadas na porção central do município, são amplamente utilizadas como espaços de lazer e recreação por pessoas atraídas pelo bem estar e relaxamento proporcionados por estes locais, 
e por autônomos que desenvolvem atividades comerciais nas adjacências das mesmas, o que as tornam importantes tanto por aspectos sociais quanto econômicos no município.

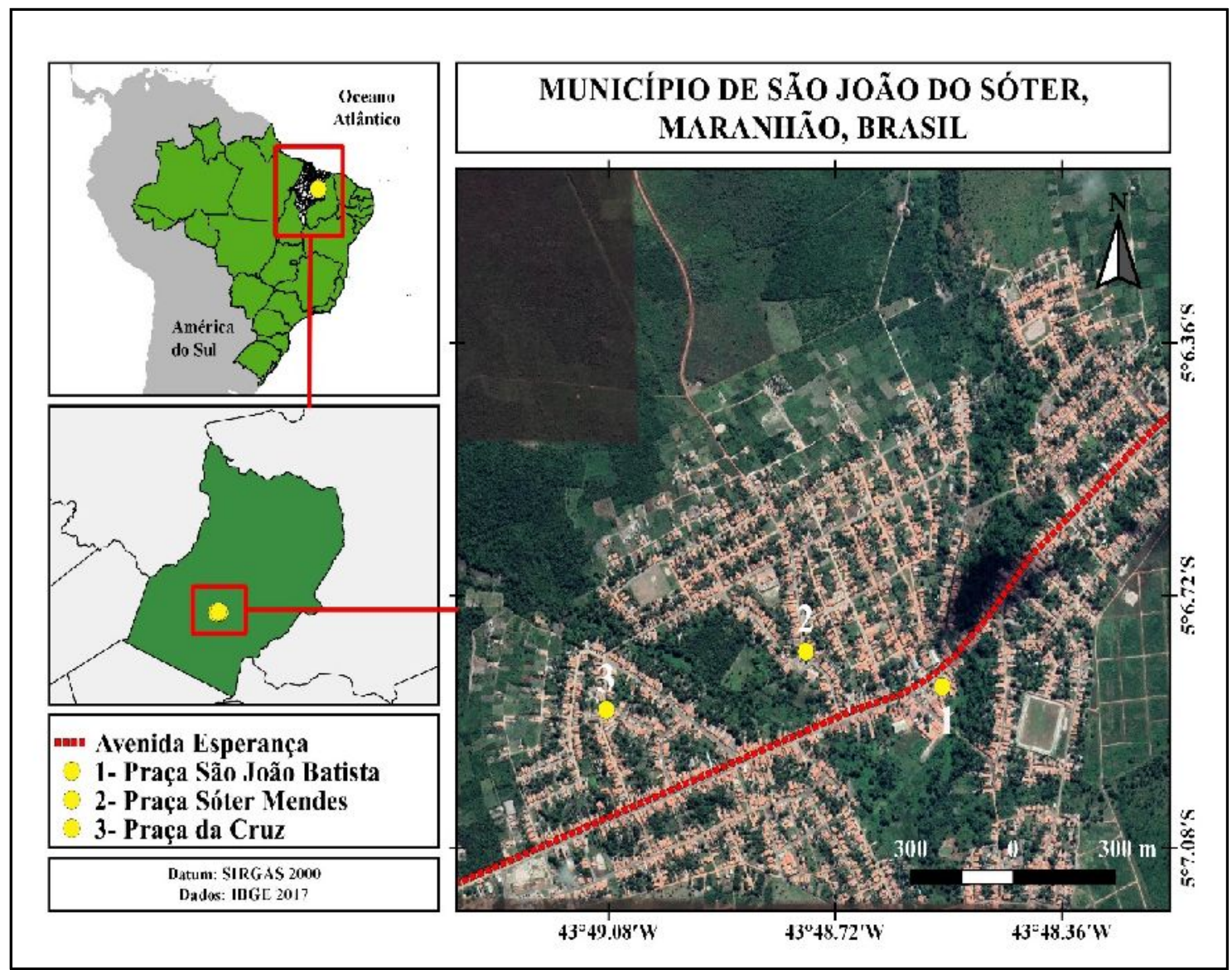

FIGURA 1. Localização do Município de São João do Sotér (MA) e visão aérea dos locais estudados. Fonte: Oliveira, (2019).

\section{Coleta de dados}

Para a aquisição dos dados, foi utilizado o método de amostragem simples, realizada através de caminhadas aleatórias em visitas mensais no município entre os meses de maio a outubro de 2018. As espécies foram identificadas com o uso de chaves dicotômicas e literatura pertinente (BARBOSA et al., 2015; OLIVEIRA et al., 2017; SILVA et al., 2017; SILVA, 2018), por consultas a especialistas e pelo uso de fotografias. O sistema de classificação botânica utilizado foi o APG IV (2016). Os nomes científicos das espécies estão de acordo com o The Plant List (2019) e Tropicos (2019). Quanto à origem fitogeográfica (nativa ou exótica), foi utilizada a base de dados da Lista da Flora do Brasil (2019). Entretanto, as classificadas como cultivadas ou naturalizadas, neste estudo, foram denominadas exóticas.

Neste estudo, foi calculada a frequência relativa e absoluta de cada espécie. Para a frequência relativa, foi calculada pela razão entre o número de indivíduos da espécie e o número total de indivíduos dentro de cada grupo multiplicada por 100 , de acordo com metodologia utilizada por Schwab et al. (2014). A diversidade florística das áreas estudas foi determinada utilizando o Índice de Shannon-Wiener $\left(H^{\prime}\right)$, gerado no software Microsoft Office Exel ${ }^{\circledR} 2013$. 


\section{RESULTADOS E DISCUSSÃO}

Foram listados 311 indivíduos, pertencentes a 31 espécies vegetais, 29 gêneros, distribuídos em 20 famílias botânicas (Tabela 1). As famílias Apocynaceae, Asparagaceae e Bignoniaceae, ambas com três espécies, foram as mais representativas em número de espécies, somando no total, cerca de $30 \%$ das espécies. Essas famílias foram as mais representativas nos trabalhos de Silva et al. (2017) com a arborização de canteiros e praças em Tuparetama-PE, também em praças de Curitiba-PR e São Gabriel- RS (VIEZZER et al., 2018; TEIXEIRA et al., 2016).

TABELA 1. Espécies utilizadas no paisagismo do município de São João do SóterMA.

\begin{tabular}{|c|c|c|c|c|c|c|}
\hline Família & Nome Cientifico & $\begin{array}{l}\text { Nome } \\
\text { popular }\end{array}$ & Hábito & Origem & FA & FR (\%) \\
\hline \multirow{3}{*}{ Asparagaceae } & Agave americana L. & Piteira & Herb. & $E$ & 27 & 7,91 \\
\hline & Sansevieria trifasciata Prain & $\begin{array}{l}\text { Espada de São } \\
\text { Jorge }\end{array}$ & Herb. & $E$ & 52 & 15,24 \\
\hline & Furcraea foetida (L.) Haw. & Furcréia & Árv. & $E$ & 7 & 2,05 \\
\hline \multirow[t]{2}{*}{ Arecaceae } & $\begin{array}{c}\text { Copernicia prunifera (Mill.) } \\
\text { H.E.Moore }\end{array}$ & Carnaúba & Árv. & $\mathrm{N}$ & 66 & 19,35 \\
\hline & Veitchia joannis H.Wendl. & Palmeira-véitia & Árv. & $E$ & 21 & 6,15 \\
\hline \multirow[t]{3}{*}{ Apocynaceae } & $\begin{array}{l}\text { Catharanthus roseus (L.) } \\
\text { G.Don }\end{array}$ & Boa Noite & Árv. & $E$ & 11 & 3,22 \\
\hline & Plumeria rubra L. & $\begin{array}{l}\text { Jasmim- } \\
\text { Manga }\end{array}$ & Árv. & $E$ & 5 & 1,46 \\
\hline & Allamanda angustifolia Pohl & Espirradeira & Árv. & $\mathrm{N}$ & 1 & 0,29 \\
\hline \multirow{2}{*}{ Anacardiaceae } & Mangifera indica L. & Mangueira & Árv. & $E$ & 3 & 0,87 \\
\hline & Spondias purpurea L. & Ceriguela & Árv. & $\mathrm{N}$ & 1 & 0,29 \\
\hline Araceae & $\begin{array}{c}\text { Dieffenbachia seguine } \\
\text { (Jacq.) Schott }\end{array}$ & $\begin{array}{l}\text { Comigo } \\
\text { Ninguém Pode }\end{array}$ & Herb. & $E$ & 1 & 0,29 \\
\hline \multirow{3}{*}{ Bignoniaceae } & $\begin{array}{l}\text { Handroanthus heptaphyllus } \\
\text { (Vell.) Mattos }\end{array}$ & Ipê Rosa & Árv. & $\mathrm{N}$ & 4 & 1,17 \\
\hline & $\begin{array}{c}\text { Handroanthus serratifolius } \\
\text { (Vahl) S.Grose }\end{array}$ & Ipê Amarelo & Árv. & $\mathrm{N}$ & 8 & 2,34 \\
\hline & $\begin{array}{c}\text { Tecoma stans (L.) Juss. ex } \\
\text { Kunth }\end{array}$ & Ipê de jardim & Árv. & $E$ & 3 & 0,87 \\
\hline \multirow{2}{*}{ Cactaceae } & $\begin{array}{c}\text { Cereus jamacaru } \\
\text { DC. }\end{array}$ & Mandacaru & Arb. & $E$ & 9 & 2,63 \\
\hline & Pereskia grandifolia Haw. & Rosa-Madeira & Arb. & $\mathrm{N}$ & 3 & 0,87 \\
\hline Cycadaceae & Cycas revoluta Thunb. & Palmeira-Sagu & Arb. & $E$ & 1 & 0,29 \\
\hline Combretaceae & Terminalia catappa L. & Amêndoa & Herb. & $E$ & 1 & 0,29 \\
\hline \multirow{2}{*}{ Euphorbiaceae } & Euphorbia milii Des Moul. & Coroa de Cristo & Herb. & $E$ & N.I & N.I \\
\hline & $\begin{array}{l}\text { Codiaeum variegatum (L.) } \\
\text { Rumph. ex A.Juss. }\end{array}$ & Croton & Arb. & $E$ & 7 & 2,05 \\
\hline Fabaceae & Arachis repens Handro & $\begin{array}{c}\text { Grama- } \\
\text { Amendoim }\end{array}$ & Herb. & $\mathrm{N}$ & N.I & N.I \\
\hline Malvaceae & Hibiscus rosa-sinensis L. & Hibisco & Arb. & $E$ & 2 & 0,58 \\
\hline Meliaceae & Azadirachta indica A. Juss. & Nim Indiano & Árv. & $E$ & 26 & 7,62 \\
\hline Myrtaceae & $\begin{array}{l}\text { Syzygium jambos (L.) } \\
\text { Alston }\end{array}$ & Jambo & Árv. & $E$ & 3 & 0,87 \\
\hline
\end{tabular}




\begin{tabular}{|c|c|c|c|c|c|c|}
\hline & $\begin{array}{l}\text { Syzygium cumini (L.) } \\
\text { Skeels }\end{array}$ & Azeitona & Árv. & $E$ & 2 & 0,58 \\
\hline Nyctaginaceae & Bougainvillea glabra Choisy & Buganvile & Arb. & $\mathrm{N}$ & 12 & 3,51 \\
\hline Plantaginaceae & $\begin{array}{l}\text { Russelia equisetiformis } \\
\text { Schltdl. \& Cham. }\end{array}$ & Flor-de-coral & Herb. & $E$ & 28 & 8,21 \\
\hline Poaceae & Bambusa vulgaris Schrad & Bambú & Arb. & $E$ & 1 & 0,29 \\
\hline Portulacaceae & Portulaca grandiflora Hook & Onze-horas & Herb. & $\mathrm{N}$ & N.I & N.I \\
\hline Rubiaceae & Ixora chinensis Lam. & Ixora-Vermelha & Arb. & $E$ & N.I & N.I \\
\hline Rutaceae & $\begin{array}{l}\text { Murraya paniculata (L.) } \\
\text { Jack }\end{array}$ & $\begin{array}{l}\text { Jasmim- } \\
\text { Laranja }\end{array}$ & Árv. & $E$ & 2 & 0,58 \\
\hline
\end{tabular}

Nota: Hábito (Arv. = arbóreo, Arb. = arbustivo, Herb. = herbáceo), FA = Frequência Absoluta; $\mathrm{FR}(\%)=$ Frequência Relativa (\%); N.I = Número Indeterminado.

As famílias Apocynaceae e Bignoniaceae destacam-se por possuírem elevada riqueza de espécies arbóreas e arbustivas com belas flores, e por isso, são amplamente utilizadas como ornamentais na arborização de ruas e praças ( ARRUDA et al., 2012; SANTOS et al., 2013). A família Asparagaceae, possui inúmeras espécies com características perenes ou anuais, flores vistosas e a uma baixa manutenção, que fazem com que os indivíduos dessa família, sejam bastante utilizados no paisagismo como ornamentais, não só no Brasil, mas em todo o mundo.

Neste estudo, o índice de diversidade de Shannon-Wiener $\left(\mathrm{H}^{\prime}\right)$ foi de 2,56, similar ao encontrado em outros trabalhos realizados no Maranhão, como o de 2,75 encontrado por Costa et al. (2016) no município de Caxias, e o de 2,43 obtido por Oliveira et al. (2017) em Aldeias Altas. O valor encontrado em São João do Sóter demostra-se intermediário a esses dois municípios e ressalta a similaridade na diversidade florística das áreas verdes (praças e avenidas) dos municípios da Região do Leste Maranhense. Entretanto, é considerado baixo, quando comparado ao de 3,34 encontrado por Maria et al. (2016) em vias públicas de Itanhaém-SP, que consideram o índice acima de 3 como uma boa diversidade de espécies.

No município de São João do Sóter, constatou-se que $71 \%$ das espécies utilizadas na arborização são de origem exótica (Figura 2). A predominância da utilização de espécies exóticas tem sido observado em diversas cidades brasileiras, conforme é apontado em outros estudos, como no levantamento das espécies arbóreas em Farol-PR (MONTEIRO et al., 2013), na análise da arborização de praças no Bairro da Tijuca-RJ (FREITAS et al., 2015), no diagnóstico florísticoestrutural da composição arbórea de praças em São Gabriel-RS (OLIVEIRA-NEVES et al., 2016), na Avaliação da arborização da Praça Barão de Araras em Araras-SP (MARTINS ; CORREA, 2016), no levantamento florístico em Lages-SC (BASTOS et al., 2016), no levantamento das espécies utilizadas na ornamentação em RegistroSP (FERRAZ et al., 2017) e na avaliação das espécies arbóreas de Planalto-BA (SILVA et al., 2012), corroborando com Lorenzi et al. (2003), que afirmam que $80 \%$ das cidades brasileiras são arborizadas com a maioria de espécies exóticas. 


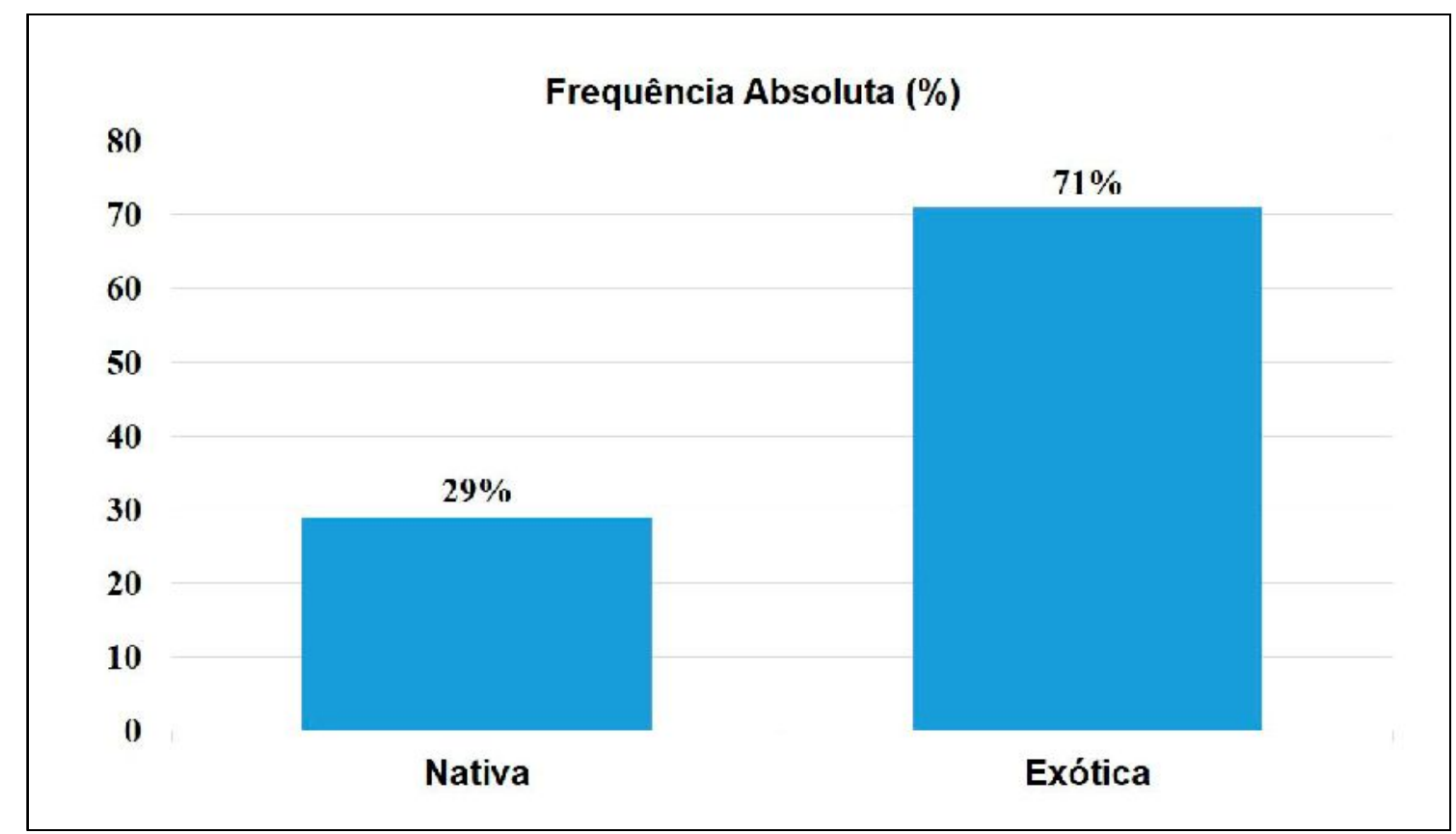

FIGURA 2. Origem das espécies vegetais inventariadas em São João do Sóter-MA.

Pelo observado, tanto nas três praças como na avenida Esperança do Município de São do Sóter são compostas, em sua maioria, por espécies exóticas (Figura 3). Na praça São João Batista, localizada no centro da cidade, foi encontrado o maior número de espécies (dezoito), entretanto, apenas quatro são nativas. No entanto, a praça Sotér Mendes, com seis espécies, apresentou uma baixa riqueza florística em comparação aos demais locais estudados, e uma composição exclusiva de espécies exóticas. Esses resultados evidenciam não só a distribuição desigual das espécies (nativas e exóticas) nos locais estudados, como a preferência pelas espécies exóticas e a baixa diversidade da flora nativa regional utilizadas nesses locais.

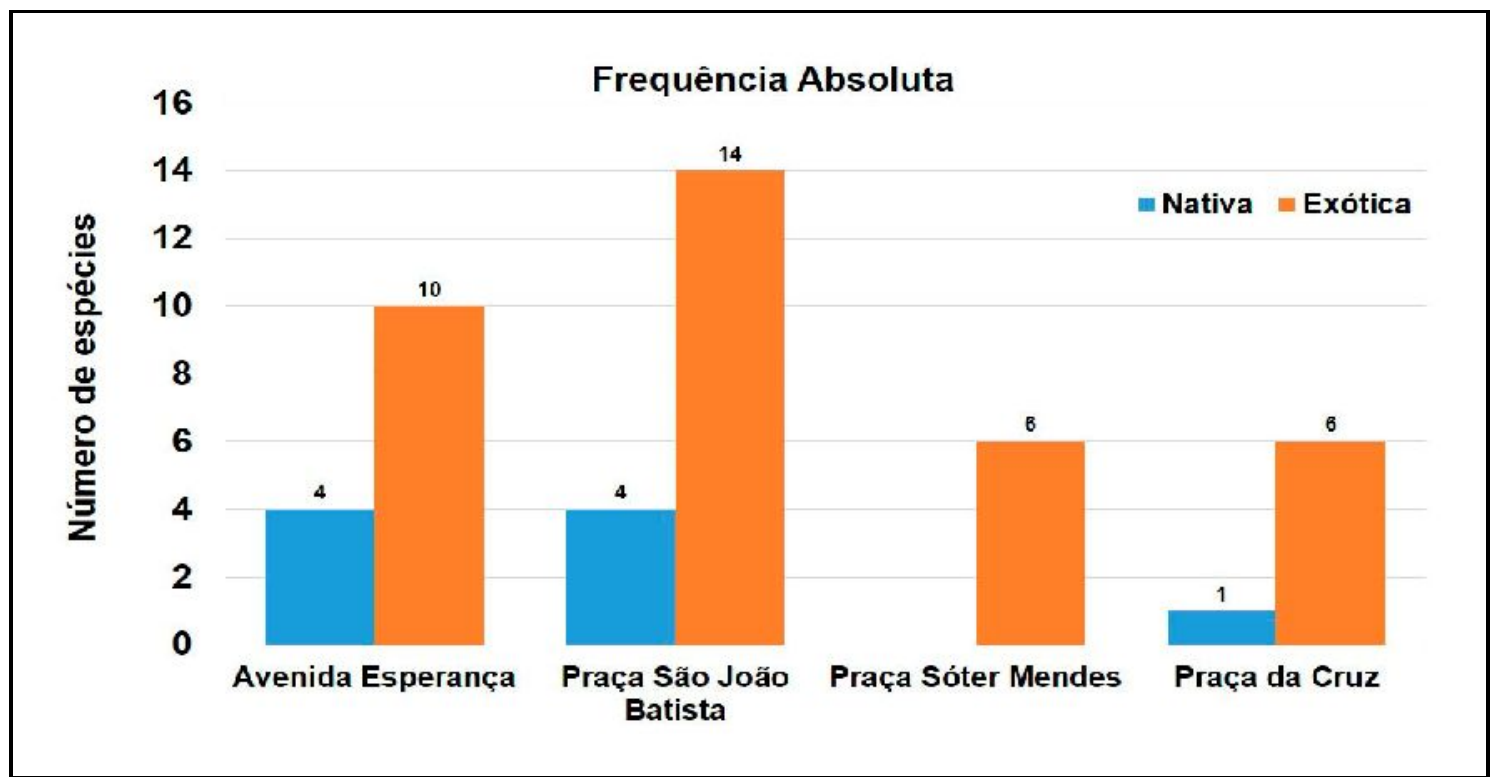

FIGURA 3. Número de espécies vegetais encontradas nos locais estudados em São João do Sóter-MA. 
Atualmente, de forma geral, nota-se a baixa diversidade das espécies utilizadas no paisagismo dos espaços públicos e, principalmente, do uso das espécies locais na arborização dos centros urbanos, mesmo diante da variedade da flora nativa de cada região. Entretanto, segundo Biondi e Pedrosa-Macedo (2008) a vegetação introduzida nas cidades, em áreas públicas (praças e a arborização de ruas), dependem e têm grande influência da administração municipal, e da escolha da população local nas residências, áreas particulares e calçadas.

As espécies exóticas possuem diversas vantagens, como crescimento o rápido, resistência a pragas, sombreamento e a grande capacidade adaptativa ao clima e recursos do novo ambiente em que estão sendo inseridas. Entretanto, esses mesmos benefícios podem torna-las prejudiciais não só do ponto de vista socioeconômicos, como ecológicos, uma vez que estás afetam diretamente no desenvolvimento das espécies nativas, competindo com as mesmas por território, água, luz e nutrientes (BLUM et al., 2008).

Segundo Moser et al. (2017) é importante a escolha de espécies nativas da região, pois, além de favorecer a manutenção da fauna local, ainda contribuem com a valorização das espécies da região. A introdução de espécies nativas contribui para a preservação, conservação do equilíbrio biológico e sustentabilidade ambiental da flora e fauna local, tanto por suas características de adaptabilidade ao meio, quanto pela preservação da biodiversidade, além de possuírem relação afetiva da população local com exemplares marcantes, referenciais ou sentimentais (CEMIG, 2011).

A arborização pode atuar nessa melhoria do ambiente urbano, pois exerce funções importantes ligadas a aspectos ecológicos, estéticos e sociais (WEIRICH et al., 2015). Entretanto, as principais dificuldades do uso de árvores nativas na arborização urbana são as de encontrar no mercado uma diversidade de espécies nativas passíveis de serem empregadas na arborização das cidades, a de reconhecimento do papel destas espécies atreladas ao uso urbano e a escassez de encontrar bibliografia disponível (CEMIG, 2011).

Segundo Labaki et al. (2012) as árvores, isoladas ou em grupos, atenuam em grande parte da radiação incidente, impedindo que sua totalidade atinja o solo ou as construções, uma vez que o sombreamento atenua a radiação solar incidente e, consequentemente, o aquecimento das superfícies, reduzindo a temperatura superficial destas, através de processos evapotranspiratórios, que atuam no resfriamento das folhas e do ar adjacente.

A elevada utilização de espécies exóticas na arborização de áreas verdes urbanas está relacionada a um reflexo de tendências paisagísticas, e pelo desconhecimento por parte da população e órgãos governamentais acerca da riqueza e utilização de espécies da flora nativa, associado a falta de planejamento e dificuldade na obtenção de mudas de espécies da flora regional (LINDENMAIER; SANTOS, 2008). Assim, o uso das espécies exóticas pode se tornar um problema, quando essas espécies passam a dominar o ambiente e a causar danos às espécies nativas e ao próprio funcionamento dos ecossistemas, podendo causar até a extinção das espécies nativas (BIONDI; PEDROSA-MACEDO, 2008).

Portanto, na arborização de locais como praças e avenidas, dentro de um planejamento adequado, é preferível a utilização de espécies nativas pelos inúmeros benefícios que possuem em detrimento das exóticas. Segundo Cemig (2011), as principais vantagens em se utilizar espécies nativas, são: a integração a um sistema organizado onde cada espécie contribui com a outra, de diversas maneiras (sombra, 
água, proteção física, local de reprodução etc.); a maior tendência a serem resistentes a pragas e doenças, pois são mais adaptadas ao ecossistema regional; a relação mais harmoniosa entre os fatores ambientais disponíveis e os necessários para a árvore; a contribuição para a manutenção do ecossistema local e, por conseguinte, global, através da preservação da fauna e flora nativas de cada região.

A espécie nativa de maior uso local foi Copernicia prunifera (Mill.) H.E.Moore (Carnaúba) com 66 indivíduos, correspondendo a cerca de $22 \%$ do total encontrado neste inventário. A presença de $C$. prunifera também foi observada compondo a vegetação paisagística de praças tanto de outros estados brasileiros, como em Picos-PI (SILVA et al. 2018), quanto em avenidas de outros municípios do Maranhão, no município de Aldeias Altas-MA (OLIVEIRA et al. 2017), evidenciando assim, o potencial ornamental para essa espécie, que já é amplamente utilizada pela indústria (produção de papel, cera, medicamentos, dentre outros), também na arquitetura e artesanato, principalmente na região Nordeste do Brasil.

O município de São João do Sóter está inserido em uma área fitogeográfica do Domínio Cerrado, e este, assim como em outras extensões do mesmo pelo Brasil, vem sofrendo com a remoção de áreas florestais nativas, queimadas anuais e extinção de espécies. E nesse sentido, ressalta-se a importância da arborização e introdução de espécies nativas para os ecossistema urbano municipal, uma vez que as árvores abrigam uma infinidade de seres vivos, como insetos, líquens, pássaros, enriquecendo e aumentando biodiversidade local. Pois, algumas espécies vegetais, com ênfase nas frutíferas nativas, são responsáveis pelo abrigo, nidificação e alimentação de aves, assegurando-Ihes condições de sobrevivência, assim como atuarem como corredores ecológicos, viabilizando a conexão entre as populações de fauna de fragmentos maiores, garantindo lhes assim, um maior sucesso ecológico para essas espécies (MTAU, 2015).

O ideal para a arborização urbana do município de São João do Sóter, de acordo com o manual da arborização urbana proposto por Pivetta e Silva Filho (2002) seria a introdução de espécies nativas como Handroanthus serratifolius (Vahl) S.Grose (Ipê Amarelo); Handroanthus heptaphyllus (Vell.) Mattos (Ipê Rosa); Handroanthus impetiginosus (Mart. ex DC.) Mattos (Ipê Roxo); Licania tomentosa (Benth.) Fritsch (Oiti); Byrsonima crassifolia (L.) Kunth (Murici), dentre outras que proporcionem benefícios para a fauna e a polução local.

Neste estudo, as espécies Euphorbia milii Des Moul. (Coroa de Cristo), Ixora chinensis Lam. (Ixora-vermelha), Arachis repens Handro (Grama-amendoim), Portulaca grandiflora Hook (onze-horas), não puderam ter seu número de indivíduos e frequências determinadas, pois as mesmas apresentaram-se, respectivamente, tanto em forma de cercas-vivas plantadas em grupos irregulares e renques, ou em forma de gramando reptante, o que inviabilizou a quantificação dos indivíduos.

Portanto, diante do panorama atual do paisagismo do município, sugere-se a criação de um plano diretor municipal, que contemple a introdução e valorização da Flora nativa local, e que utilize critérios técnicos ideais e específicos para a arborização das áreas verdes urbanas, principalmente, no que se refere à escolha de espécies adequadas, evitando a homogeneidade desses ambientes, garantindo assim, seus benefícios ecológicos e sociais, resultando em melhorias para a qualidade de vida da população urbana. 


\section{CONCLUSÃO}

Neste estudo, constatou-se que $71 \%$ das espécies utilizadas no paisagismo das praças e avenida do município, são de origem exótica. Também, que o uso desproporcional de indivíduos da mesma espécie nos locais amostrados, acarreta em riscos para a diversidade florística e faunística destes locais. É que torna-se necessário a reavaliação por parte dos órgãos competentes a cerca a introdução das espécies utilizadas no paisagismo do município, para que esses locais se tornem-se cada vez mais agradáveis para a população e ecologicamente contextualizados.

\section{REFERÊNCIAS}

APG IV. An update of the Angiosperm Phylogeny Group classification for the orders and families of flowering plants: APG IV. Botanical Journal of the Linnean Society, Oxford, v. 181, n. 1, p. 1-20, 2016. Disponível em: < http://reflora.jbrj.gov.br/downloads/2016_GROUP_Botanical\%20Journal\%20of\%20th e\%20Linnean\%20Society.pdf>.

ALVAREZ, C. A.; STAPE, J. L.; SENTELHAS, P. C.; GONÇALVES, J. L. M.; SPAROVEK, G. Köppen's climate classification map for Brazil. Meteorologische Zeitschrift, Stuttgart, v. 22, n. 6, p. 711-728, 2014. Doi: 10.1127/09412948/2013/0507

ARRUDA, A. L. A.; SOUZA, D. G.; VIEIRA, C. J. B.; OLIVEIRA, R. F.; PAVAN, F. R.; FUJIMURA, C. Q. L. Análise fitoquímica e atividade antimicobacteriana de extratos metanólicos de Jacaranda cuspidifolia Mart. (Bignoniaceae). Revista Brasileira de Plantas Medicinais, v.14, n.2, p.276-281, 2012. Doi: http://dx.doi.org/10.1590/S1516-05722012000200004.

BONFANTI, C. G.; VALE, G. M.; RIBEIRO, J. G. Verificação espacial e determinação do índice de áreas verdes da cidade de Sinop-MT. Revista Nativa, v. 6, n. 1, 2017. Disponível em:< http://revistanativa.com/index.php/revistanativa/article/view/325>.

BASTOS, F. E. A.; CAMARGO, S. S.; MENEGUZZI, A.; KRETZSCHMAR, A. A.; RUFATO, L. Levantamento florístico e características das espécies em praças públicas em Lages-SC. Revista da Sociedade Brasileira de Arborização Urbana, Piracicaba, v. 11, n. 1, p. 34-42, 2016. Disponível em:< https://docplayer.com.br/69977214-Levantamento-floristico-e-caracteristicas-dasespecies-em-pracas-publicas-em-lages-sc.html>.

BARBOSA, L. A.; LOPES, C. G. R.; LOPES, W. G. R. Levantamento das espécies vegetais das praças de São João dos Patos-MA. Revista da Sociedade Brasileira de Arborização Urbana, Piracicaba, v. 10, n. 1, p. 19-29, 2015. Disponivelem:<https://www.redib.org/recursos/Record/oai_articulo987660levantamen toesp\%C3\%A9cies-vegetais-pra\%C3\%A7as-jo\%C3\%A3o-patos--ma>.

BIONDI, D.; PEDROSA-MACEDO, J. H. Plantas invasoras encontradas na área urbana de Curitiba (PR). Revista Floresta, Curitiba, v. 38, n. 1, p. 129-144, 2008. Disponível em: < https://revistas.ufpr.br/floresta/article/view/11034/7505>. 
BLUM, C. T.; BORGO, M.; SAMPAIO, A. C. F. Espécies exóticas invasoras na arborização de vias públicas de Maringá-PR. Revista da Sociedade Brasileira de Arborização Urbana, Piracicaba, v. 3, n. 2, p. 78-97, 2008. Disponível em: https://docplayer.com.br/46210925-Especies-exoticasinvasorasnaarborizacao-devias-publicas-de-maringa-pr.html>.

COSTA, C. F.; FONSECA, R. S.; ALMEIDA, D. B.; OLIVEIRA, M. S.; OLIVEIRA, D. S.; BRAGA, J. H. P. Espécies utilizadas na arborização em praças do município de Caxias, Maranhão. Revista da Sociedade Brasileira de Arborização Urbana, Piracicaba, v. 12, n. 1, p. 65-78, 2017.Disponivel em:< https://www.researchgate.net/publication/324679059_especies_utilizadas_na_arbori zacao_em_pracas_do_municipio_de_caxias_maranhao>.

CEMIG - Companhia Energética de Minas Gerais. Manual de arborização. Belo Horizonte: Cemig, 2011. 112 p.

CARVALHO, J. A.; NUCCI, J. C.; VALASKI, S. Inventário das Árvores Presentes na Arborização de Calçadas da Porção Central do Bairro Santa Felicidade. Revista da Sociedade Brasileira de Arborização Urbana, Piracicaba-SP, v. 5, n. 1, p. 126143, 2010. Disponível em:<https://docplayer.com.br/19676059-Inventario-dasarvores-presentes-na-arborizacao-de-calcadas-da-porcao-central-do-bairro-santafelicidade-curitiba-pr.html>.

FERRAZ, M. V.; DEL NERI, L. A.; NUNES, J. V. C. Levantamento florístico das espécies utilizadas na ornamentação da praça cidade Nakatsugawa, Registro, SP. Revista TREE DIMENSIONAL, ProFloresta - Goiânia, v. 2 n. 4; p. 45-50, 2017. Doi: 10.18677/TreeDimensional_2017B4.

FREITAS, W. K.; PINHEIRO, M. A. S.; ABRAHÃO, L. L. F. Análise da Arborização de Quatro Praças no Bairro da Tijuca, RJ, Brasil. Revista Floresta e Ambiente, v. 22, n. 1, p. 23-31, 2015. Doi: http://dx.doi.org/10.1590/2179-8087.025612

IBGE. Instituto Brasileiro de Geografia e Estatística. Disponível em:< https://cidades.ibge.gov.br/brasil/ma/sao-joao-do-soter/panorama>Acesso em: 12 Jan. 2019.

KRAMER, J. A.; KRUPEK, R. A. Caracterização florística e ecológica da arborização de praças públicas do município de Guarapuava, PR. Revista Árvore, Viçosa, v. 36, n. 4, p. 647-658, 2012. Disponível em:< http://dx.doi.org/10.1590/S010067622012000400007>.

LINDENMAIER, D. S.; SANTOS, N. O. Arborização urbana das praças de Cachoeira do Sul-RS-Brasil: fitogeografia, diversidade e índice de áreas verdes. Revista Pesquisas-Botânica, n. 59, p. 307-320, 2008.

LISTA DA FLORA DO BRASIL EM CONSTRUÇÃO 2020. Jardim Botânico do Rio de Janeiro. Disponível em: < http://floradobrasil.jbrj.gov.br/ >. Acesso em: 12 Jan. 2019. 
LABAKI, L. C.; SANTOS, R. F. S.; BUENOBARTHOLOMEI, C. L.; ABREU, L. V. A. Vegetação e conforto térmico em espaços urbanos abertos. Fórum Patrimônio, Belo Horizonte, v. 4, n. 1, p. 23-42, 2012. Disponível em:< https://www.researchgate.net/publication/260591709_Vegetacao_e_conforto_termico _em_espacos_urbanos_abertos>.

LORENZI, H.; SOUZA, H. M.; TORRES, M. A. V.; BACHER, L. B. Árvores exóticas no Brasil: madeiras, ornamentais e aromáticas. $1^{\mathrm{a}} \mathrm{ed}$. Nova Odessa: Platarum, 2003. 368p.

MOSER, P.; SILVA, A. C.; HIGUCHI, P.; SCHMITZ, V. Inventário da arborização e distribuição de praças-jardim em bairros centrais e periféricos de um município no sul do Brasil. Revista Espacios, v. 38, n. 38, p. 21-31, 2017. Disponível em:<http://www.revistaespacios.com/a17v38n38/17383821.html>.

MARIA, T. R. B.; BIONDI, D.; BROBOWSKI, R. Inventário florístico quali-quantitativo das vias púbicas de Itanhaém - SP. Revista da Sociedade Brasileira de Arborização Urbana, Piracicaba, v. 11, n. 4, p. 79-97, 2016. Disponívelem:<http://silvaurba.esalq.usp.br/revsbau/ptbr/volume11 numero42016/5pl anejamento_e_gestao_florestal_urbana.php>.

MARTINS, V. F.; CORREA, G. W. Avaliação da arborização da praça Barão de Araras (Araras-SP). Revista Ciência, Tecnologia e Ambiente, v. 4, n. 1, p. 20-29, 2016. Doi: http://dx.doi.org/10.4322/2359-6643.04106

MTAU. Manual Técnico de Urbana. 3o edição. 2015. 118 p. Disponível em:<https://www.prefeitura.sp.gov.br/cidade/secretarias/upload/meio_ambiente/MAN UAL-ARBORIZACAO_22-01-15_.pdf>.

MONTEIRO, M. R.; KURODA, C. Y.; SILVA, O. H.; CAXAMBU, M. G. Levantamento dos espécimes vegetais da arborização urbana e seus conflitos com os equipamentos públicos no município de Farol-Paraná. Revista de Geografia, Meio Ambiente e Ensino, v. 4, n. 2, p. 25-36, 2013. Disponívelem:<http://www.fecilcam.br/revista/index.php/geomae/article/viewFile/1024 /pdf_148.

MELO, E. F. R. Q.; ROMANINI, A. Praça Ernesto Tochetto: importância da sua preservação histórica e aspectos de sua arborização. Revista da Sociedade Brasileira de Arborização Urbana, Piracicaba-SP, v. 3, n. 1, p. 54-72, 2008. Disponível:< $\quad$ http://livrozilla.com/doc/960728/pra\%C3\%A7a-ernesto-tochetto-import\%C3\%A2ncia-da-sua>.

OLIVEIRA, M. S.; FERREIRA, A. W. C.; LOPES, J. R. S.; REIS, J. R.; SILVA JUNIOR, W. R.; COSTA, J. A. Espécies vegetais presentes em praças e avenidas do município de Aldeias Altas, Maranhão, Brasil. Revista da Sociedade Brasileira de Arborização Urbana, Piracicaba - SP, v. 12, n. 4, p. 13-22, 2017. Disponível em:< https://www.researchgate.net/publication/322919073_ESPECIES_VEGETAIS_PRES ENTES_EM_PRACAS_E_AVENIDAS_DO_MUNICIPIO_DE_ALDEIAS_ALTAS_MA RANHAO_BRASIL/figures? $\mathrm{l}=1>$. 
OLIVEIRA-NEVES, P.; JUNIOR, A. S. B.; LOPES, B. S.; ANDREIS, D.; GONÇALVES, E. B.; LEMOS, G. M. Diagnóstico florístico-estrutural e potencial invasor da composição arbórea de praças municipais de São Gabriel, RS, Brasil. Revista Pesquisas, botânica, n. 69, p. 227-238, 2016. Disponível em:< http://www.anchietano.unisinos.br/publicacoes/botanica/botanica69/011.pdf>.

PIVETTA, K. F. L.; SILVA FILHO, D. F. Boletim Acadêmico: Arborização Urbana. Jaboticabal: UNESP, 2002. 74p.

SILVA, L. S.; OLIVEIRA, Y. R.; SILVA, P. H.; PIMENTEL, R. M. M.; ABREU, M. C. Inventário das plantas arbustivo-arbóreas utilizadas na arborização urbana em praças públicas. Journal of Environmental Analysis and Progress, v. 3, n. 2, p. 241-249, 2018. Doi: 10.24221/jeap.3.2.2018.1834.241-249

SILVA, R. F. L.; RODRIGUES, J. S.; LUCENA, M. F. A. Avaliação das espécies vegetais utilizadas na arborização em canteiros e praças de Tuparetama, Pernambuco, Nordeste do Brasil. Revista da Sociedade Brasileira de Arborização Urbana, Piracicaba, v. 12, n. 1, p. 132-141, 2017. Disponível em:<http://docplayer.com.br/77322645-Avaliacao-das-especies-vegetais-utilizadasna-arborizacao-em-canteiros-e-pracas-de-tuparetama-pernambuco-nordeste-dobrasil.html>.

SCHEUER, J. M.; NEVES, S. M. A. S. Planejamento urbano, áreas verdes e qualidade de vida. Revista Meio Ambiente e Sustentabilidade, v. 11, n. 5, p. 5973, 2016. Disponível em: < https://www.uninter.com/revistameioambiente/index.php/meioAmbiente/article/view/5 $87>$.

SCHWAB, N. T.; GIRARDI, L. B.; NEUHAUS, M.; BACKES, F. A. A. L.; BELLÉ, R. A.; MENEGAES, J. F. Diversidade florística do bairro Nossa Senhora das Dores em Santa Maria, RS. Revista Brasileira de Horticultura Ornamental, Campinas, v. 20, n. $\quad 2, \quad$ p. $\quad 155-162, \quad 2014 . \quad$ Disponível em:< https://ornamentalhorticulture.emnuvens.com.br/rbho/article/view/563/540>.

SANTOS, A. C. B.; SILVA, M. A. P.; SANTOS, M. A. F.; LEITE, T. R. Levantamento etnobotânico, químico e farmacológico de espécies de Apocynaceae Juss. ocorrentes no Brasil. Revista Brasileira de Plantas Medicinais, v. 15, n. 3, p. 442458, 2013. Disponível em:<http://www.scielo.br/pdf/rbpm/v15n3/19.pdf>.

SILVA, A. R.; PAULA, R. C. A. L; PAULA, A.; FREITAS, L.C. Avaliação de espécies da arborização em oito praças do município de Planalto-BA. Revista Enciclopédia Biosfera, Centro Científico Conhecer - Goiânia, v. 8, n. 14; p. 10421050,2012.Disponível

em:<http://www.conhecer.org.br/enciclop/2012a/ambientais/avaliacao\%20de\%20esp ecies.pdf>.

SÃO JOÃO DO SÓTER. 2011. Relatório Diagnóstico Do Município de São João do Sóter. Disponível em:< 
http://rigeo.cprm.gov.br/xmlui/bitstream/handle/doc/15629/rel_sao_joao_soter.pdf?se quence $=1>04 / 01 / 2019$.

TROPICOS. Missouri Botanical Garden. http://www.tropicos.org/Name/13801984. Acesso em: 04/01/2019.

THE PLANT LIST. Base de dados Eletrônica. Disponível em: $<$ http://www.theplantlist.org/> Acesso em: 04/01/2019.

TEIXEIRA, I. F.; FIGUEIREDO, F. M.; TABORDA, I. G. R.; SOARES, L. M. Análise fitossociológica da praça Camilo Mércio no centro histórico de São Gabriel, RS. Revista Brasileira de Arborização Urbana, Piracicaba-SP, v. 11, n. 1, p. 01-13, 2016. Disponível em: <http://docplayer.com.br/53770736-Analise-fitossociologica-dapraca-camilo mercio-no-centro-historico-de-sao-gabriel-rs.html>.

VIEZZER, J.; BIONDI, D.; MARTINI, A.; GRISE, M. M. A vegetação no paisagismo das praças de Curitiba-PR. Revista Ciência Florestal, Santa Maria, v. 28, n. 1, p. 369-383, 2018. Doi: http://dx.doi.org/10.5902/1980509831608

WEIRICH, R. A.; CALIL, F. N.; MONTEIRO, M. M.; GONÇALVES, B. B.; NETO, C. M. S.; VENTUROLI, F. Arborização urbana para mitigação das condições microclimáticas em Goiânia, Goiás. Ecologia e Nutrição Florestal, Santa Maria-RS, v. $3, \quad$ n. 2, p. 48-58, 2015. Disponível em: < https://www.researchgate.net/publication/298725333_Arborizacao_urbana_para_miti gacao_das_condicoes_microclimaticas_em_Goiania_Goias>. 